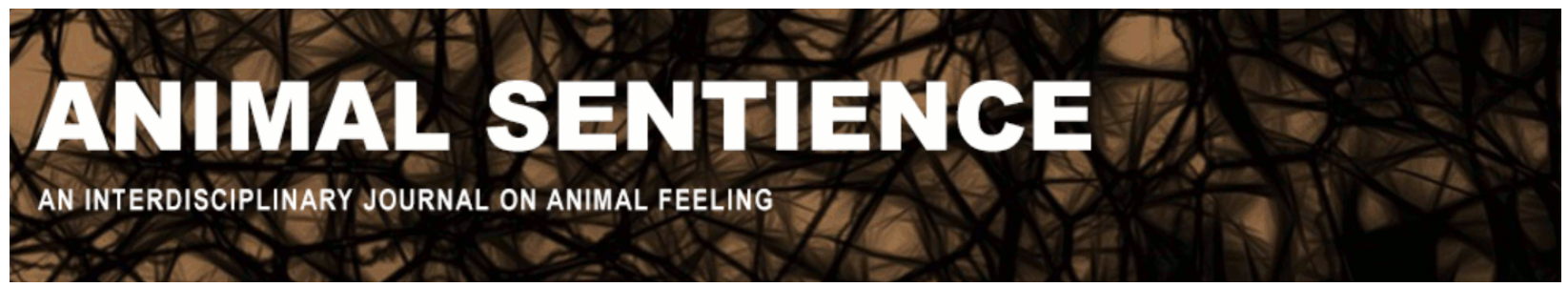

Blystad, Magnus Helgheim (2018) Human-like behavior and cognition: Not a good starting point. Animal Sentience 23(11)

DOI: $10.51291 / 2377-7478.1391$

Date of submission: 2019-01-31

Date of acceptance: 2019-02-10

(c)

This article has appeared in the journal Animal

Sentience, a peer-reviewed journal on animal

cognition and feeling. It has been made open access,

free for all, by WellBeing International and deposited

in the WBI Studies Repository. For more information,

please contact

wbisr-info@wellbeingintl.org.

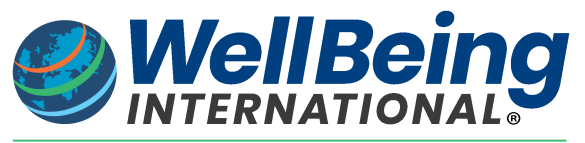

SOLUTIONS FOR PEOPLE, ANIMALS AND ENVIRONMENT 


\title{
Human-like behavior and cognition: Not a good starting point
}

Commentary on Chapman \& Huffman on Human Difference

\author{
Magnus Helgheim Blystad \\ Department of Behavioral Science, Oslo Metropolitan University
}

\begin{abstract}
Chapman \& Huffman make use of observations and studies that show how humans may not be as unique in our behaviour and cognition as previously thought. I wholeheartedly agree that our uniqueness might be small and that if it exists, it should not give our species any right to act cruelly towards other animals. However, this kind of logic can be problematic. I present a few of the issues in this commentary.
\end{abstract}

Magnus Helgheim Blystad holds an MSc Neuroscience and works on empathy and behaviour, pro-social rat behaviour and possible influencers of such behaviours. Currently a PhD candidate at Oslo Metropolitan University, he teaches Cognitive Psychology and Neuroscience in the Psychology BA program. Website

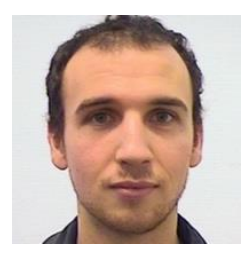

Humans are different from other animals, but we are still animals. Uniquely human traits and skills shrink in numbers as we discover variants of them in the field and in the lab, as Chapman \& Huffman (2018) describe. For cognitive abilities, it is perhaps harder to draw a line between human and non-human animals, for many reasons.

It is true that a cognitive appraisal of animals shows us that much of what we can do is within their capabilities. To Chapman \& Huffman's examples I would add discoveries from the field of rodent laboratory research. Rodent research has shown that these small mammals are capable of cooperation (Schneeberger, Dietz, \& Taborsky, 2012), helping behaviour (Bartal, Decety, \& Mason, 2011), and sharing of rewards (Hernandez-Lallement, van Wingerden, Marx, Srejic, \& Kalenscher, 2014). Why animals perform human-like behaviour is hard to grasp.

One problem is that animals do not self-report; so unless we can add data regarding mechanisms in their nervous system with a human analogue, it is hard to know exactly why an animal does one thing and not another, especially in advanced behaviour or cognitive tasks. Moreover, even where there are human analogues, interpretation problems may remain because the level of granularity needed for the observed behaviour needs to be very high in order to get a correct neural correlate (Krakauer, Ghazanfar, Gomez-Marin, Maclver, \& Poeppel, 2017).

Another counterpoint to using the seemingly convincing evidence of human-like behaviour in animals is, of course, interpretations and evidence against these discoveries. For example, in studies of rodent pro-sociality, some researchers claim to observe empathy (i.e., Bartal et al., 2011) but others disagree, both theoretically (Vasconcelos, Hollis, Nowbahari, \& Kacelnik, 2012) and experimentally (Silberberg et al., 2013). Contested claims make for poor arguments. 
The argument of similarities in species on account of similar behaviour falls apart when examples of more bestial behaviours in animals emerge, and the subsequent response by conspecifics. While cooperation in dolphins to save injured conspecifics is well known and documented (Siebenaler \& Caldwell, 1956), so are acts of sexual aggression (Sargeant, WatsonCapps, Scott, Connor, \& Mann, 2005). Of course, the horrific behaviour above is exhibited by humans as well, but humans performing similar horrible acts must answer for their crimes. Human society frowns upon and tries to remove these elements from their midst. An alpha lion killing existing cubs in his pride is not ostracised or denied mates.

I do not think that relying on surface valid behaviour is a logically sound approach. More important: it can easily lead us down a path where value is given to animals if they perform tasks humans think are interesting. That is not where we want to be.

\section{References}

Bartal, I. B.-A., Decety, J., \& Mason, P. (2011). Empathy and pro-social behavior in rats. Science, 334(December), 1427-1431.

Chapman, C. A., \& Huffman, M. A. (2018). Why do we want to think humans are different? Animal Sentience 23(1).

Hernandez-Lallement, J., van Wingerden, M., Marx, C., Srejic, M., \& Kalenscher, T. (2014). Rats prefer mutual rewards in a prosocial choice task. Frontiers in Neuroscience, 8(January), 443.

Krakauer, J. W., Ghazanfar, A. A., Gomez-Marin, A., Maclver, M. A., \& Poeppel, D. (2017). Neuroscience needs behavior: Correcting a reductionist bias. Neuron, 93(3), 480-490.

Lane-Petter, W. (1968). Cannibalism in rats and mice. Proceedings of the Royal Society of Medicine, 61(12), 1295-1296.

Sargeant, B., Watson-Capps, J., Scott, E., Connor, R., \& Mann, J. (2005). Aggression in bottlenose dolphins: Evidence for sexual coercion, male-male competition, and female tolerance through analysis of tooth-rake marks and behaviour. Behaviour, 142(1), 21-44.

Schneeberger, K., Dietz, M., \& Taborsky, M. (2012). Reciprocal cooperation between unrelated rats depends on cost to donor and benefit to recipient. BMC Evolutionary Biology, 12(1), 41.

Siebenaler, J. B., \& Caldwell, D. K. (1956). Cooperation among adult dolphins. Journal of Mammalogy, 37(1), 126-128.

Silberberg, A., Allouch, C., Sandfort, S., Kearns, D., Karpel, H., \& Slotnick, B. (2013). Desire for social contact, not empathy, may explain "rescue" behavior in rats. Animal Cognition, 17(3), 609-618.

Vasconcelos, M., Hollis, K., Nowbahari, E., \& Kacelnik, A. (2012). Pro-sociality without empathy. Biology Letters, 8(6), 910-912. 